\title{
MUDANÇA ORGANIZACIONAL: OS EFEITOS DOS ESTILOS DE LIDERANÇA NO COMPORTAMENTO DOS TRABALHADORES
}

\section{ORGANIZATIONAL CHANGE: THE EFFECTS OF LEADERSHIP STYLES ON THE BEHAVIOR OF WORKERS}

\author{
Renata Veloso Santos Policarpo \\ Instituto Federal de Minas Gerais / Universidade Federal de Minas Gerais \\ renataveloso@ifmg.edu.br \\ Renata Simôes Guimarães e Borges \\ Universidade Federal de Minas Gerais \\ renatasg@face.ufmg.br
}

Submissão: 20/04/2016

Aprovação: 10/02/2017 


\section{RESUMO}

O objetivo deste ensaio é refletir sobre as temáticas estilos de liderança e mudança organizacional. Mais especificamente, este estudo procura identificar como os estilos de liderança podem influenciar o comportamento individual de resistência ou aceitação dos trabalhadores em relação à mudança organizacional. Como resultado, foi possível também propor algumas hipóteses indicando possibilidades para futuras pesquisas. Procedeu-se ao resgate na literatura sobre as principais correntes teóricas sobre mudança organizacional, focando principalmente nas reações individuais à mudança e nos estilos de liderança considerando as abordagens atuais denominadas liderança transacional e transformacional. Em seguida, foram identificadas as possíveis relações entre os estilos de liderança e as reações individuais à mudança organizacional, podendo esta assumir o caráter de cooperação ou de resistência. A literatura apresenta algumas indicações de que líderes transformacionais podem direcionar seus seguidores para um comportamento de aceitação às mudanças empreendidas, enquanto os líderes transacionais seriam aqueles que com sua atuação levariam seus seguidores a assumirem um comportamento de resistência. Algumas implicações para pesquisas futuras são discutidas.

Palavras-chave: Liderança, Mudança Organizacional, Estilos de Liderança, Reações à Mudança Organizacional, Resistência à Mudança Organizacional. 


\begin{abstract}
The aim of this research is to reflect on the themes leadership styles and organizational change. Specifically, this study seeks to identify how leadership styles may influence employees' behaviors of acceptance or resistance to organizational change. As result, we propose some hypotheses indicating new possibilities to future research. We present a literature review on the major theoretical perspectives about organizational change, focusing on individual reactions to change and on the leadership styles-transactional and transformational styles. Then, the literature review identifies possible relationships between the leadership styles and individual reactions to organizational change, which can be featured as cooperative or resistant. The literature presents some indications that transformational leaders can manage their followers to a positive behavior, cooperating with the proposed changes, while transactional leaders would encourage their follower to somehow present a resistance behavior. Some implications for future research are presented.
\end{abstract}

Keywords: Leadership, Organizational Change, Leadership Styles, Reactions to Organizational Change, Resistance to Organizational Change. 


\section{INTRODUÇÃO}

O tema mudança organizacional está cada vez mais frequente nas discussões acadêmicas teóricas e empíricas em decorrência, principalmente, da necessidade de minimizar as chances de insucesso ao compreender as causas e consequências desses processos. Vários autores (MAURER, 1996; WADDELL; SOHAL, 1998; DEL VAL; FUENTES, 2003) enfatizam que as razões para o fracasso de muitas iniciativas de mudança organizacional têm origem nas reações individuais, sobretudo quando esses comportamentos assumem a forma de resistência. Outras pesquisas acrescentam que qualquer iniciativa de mudança na organização tem alto potencial de insucesso se os funcionários não estiverem propensos a mudar ou se acreditam que a mudança tem chances de fracassar (SEIJTS; ROBERT, 2011). Nesse sentido, o pressuposto básico é que um desempenho positivo depende, na maioria das vezes, da maneira como os membros da organização se comportam e da disposição e capacidade de se transformarem e se reinventarem (LEWIN, 1951; MAS, 2008; MARQUES, 2012).

Por outro lado, as organizações como um ambiente em constante transformação podem gerir os processos de mudanças de diversas formas. Estas organizações admitem que o envolvimento do funcionário é um dos fatores de sucesso da mudança, pois os indivíduos precisam adaptar constantemente seu comportamento para ajustar às novas demandas empreendidas pela organização. Nesse sentido, os membros organizacionais podem ver a mudança como uma oportunidade ou como uma ameaça para sua vida pessoal e profissional (SEIJTS; ROBERTS, 2011). Os funcionários que percebem a mudança como positiva, em geral, tendem a apresentar níveis de satisfação com o trabalho mais alto do que aqueles que percebem as mudanças como negativas (LAMBERT; HOGAM, 2010).

Em tais situações, as reações individuais à mudança organizacional ocupam um papel crucial no gerenciamento do processo de mudança e devem ser seriamente consideradas nas ações organizacionais que visam alcançar os objetivos das transformações (DEL VAL; FUENTES, 2003). A literatura que abarca as discussões sobre o tema reconhece que o comportamento do indivíduo pode variar entre a tentativa agressiva de minar esforços, no caso a resistência ativa, até um sincero comprometimento com a causa, que seria a aceitação ou cooperação (JUDSON, 1980; KOTTER; SCHLESINGER,1994). No contexto organizacional, o gestor enquanto líder desempenha um papel fundamental para manter a confiança do funcionário na organização e reduzir a descrença nos processos de mudança (LAMBERT; HOGAM, 2010). Por isso, torna-se importante compreender, no contexto da 
organização, como a mudança afeta as pessoas e como os líderes se comportam para minimizar, na medida do possível, o impacto dos sentimentos de insatisfação e insegurança que podem levar ao surgimento da resistência (SZABLA, 2007).

Considerando o pressuposto de que em um processo de mudança ocorre certa ruptura do status quo (LEWIN, 1951), alguns pesquisadores têm discutido como os líderes devem agir quando orientam suas equipes para a mudança. No entanto, pouca atenção tem sido dada à perspectiva do funcionário (OREG; BERSON, 2011), apesar do consenso em relação ao seu papel crítico na determinação do sucesso de qualquer mudança organizacional (BARTUNEK et al., 2006). Estudos anteriores têm confirmado que as atitudes e reações dos funcionários à mudança organizacional são traduzidas na forma de resultados organizacionais, como desempenho, satisfação no trabalho e bem estar psicológico (OREG, 2006; RAFFERTY; GRIFFIN, 2006; FUGATE; KINICKI; PRÙCIA, 2008; MARQUES; BORGES; NEVES, 2016). Mas, somente poucos estudos têm investigado o papel dos líderes no comportamento dos funcionários (OREG; BERSON, 2011).

Diante da necessidade de avançar nessas discussões, este trabalho objetiva aprofundar o conhecimento sobre a temática mudança organizacional fazendo uso da perspectiva das abordagens em liderança que se ancoram nos estilos de liderança transacional e transformacional. Na liderança transacional um líder enxerga a relação líder-liderado como um processo de troca, onde o subordinado estabelece um vínculo com o líder condicionado ao recebimento de uma recompensa negociada anteriormente (HOLLANDER, 1978, YUKL, 1989). Já a liderança transformacional, que envolve mais que o intercâmbio de experiências e influências entre líderes e liderados, é caracterizada como um processo que motiva seguidores apelando aos valores morais e aos ideais mais elevados (BURNS, 1978; DIAS; BORGES, 2015). Nesse sentido, segundo Burns (1995) os líderes transformacionais são capazes de definir e articular uma visão para suas organizações e de influenciar seus seguidores a participar de sua efetivação.

Considerando que os líderes têm forte impacto sobre as ações organizacionais e, que as reações dos funcionários têm papel-chave na determinação do sucesso das mudanças organizacionais (BARTUNEK et al., 2006), torna-se importante construir um quadro teórico vinculando o papel dos líderes ao comportamento cooperativo ou resistente dos funcionários. Apesar da quantidade limitada de pesquisas que ligam esses dois fatores, as bases conceituais existentes (OREG; BERSON, 2011), juntamente com resultados empíricos de outros contextos, podem inspirar predições para este trabalho. Assim, convergir as perspectivas 
teóricas sobre as reações individuais à mudança organizacional e o estilo da liderança pode ajudar a explicar e compreender as causas e consequências da mudança na organização (BERSON; OREG; DVIR, 2008). Portanto, este estudo tem como objetivo refletir sobre as reações individuais à mudança organizacional e o papel dos estilos de liderança neste processo. Mais especificamente, este estudo procura identificar como os estilos de liderança podem influenciar o comportamento individual de resistência ou aceitação dos trabalhadores em relação à mudança organizacional, temática tratada a seguir.

\section{MUDANÇA ORGANIZACIONAL}

Na mesma proporção em que as organizações foram impelidas a aumentar o seu grau de preocupação e atenção em relação aos processos de mudança, os estudos sobre o tema ganharam relevância. Ao adentrar na literatura constata-se que vários trabalhos surgiram para entender, analisar e explicar o fenômeno e suas implicações nas organizações (NADLER; TUSHMAN, 1990; BLUMENTHAL; HASPESLAGH, 1994; GREENWOOD; HININGS, 1996; LIMA; BRESSAN, 2003; OREG, 2006; BORGES; MARQUES, 2011). Na perspectiva de Lima e Bressan (2003), a temática não é uma questão nova na teoria das organizações. Embora ainda tenha campo de estudo, o seu conceito permanece elusivo pela característica de sua própria natureza e pela dificuldade inerente em se definir seus limites.

Conceituando mudança organizacional Nadler e Tushman (1990) afirmam que ela pode ser considerada uma resposta da organização às transformações que vigoram no ambiente, com o intuito de manter a congruência entre os componentes organizacionais: trabalho, pessoas, cultura e estrutura. Barnett e Carroll (1995) destacam que por definição, a mudança envolve uma transformação da organização entre dois momentos, ou seja, a comparação da organização antes e depois da transformação. Em outra vertente, Lines (2005) define mudança organizacional como uma alteração formalmente planejada que pode contemplar estrutura, processos e sistemas e cujo objetivo é atingir metas organizacionais.

As concepções de Lima e Bressan (2003) e Neiva (2004) denotam pontos convergentes entre essas definições que determinam o tipo de mudança empreendida com a forma de condução do processo de transformação organizacional. Assim, as autoras consideram a mudança como qualquer alteração implementada nos componentes organizacionais (pessoas, trabalho, estrutura formal, cultura, etc) que caracterizam a 
organização como um todo, ou nas suas relações com o seu ambiente, que pode ser planejada ou não, acarretando consequências relevantes (positivas ou negativas) para os resultados organizacionais ou para sua sobrevivência. Com isso, mesmo as mudanças planejadas podem gerar incertezas e turbulências no ambiente organizacional.

Sob essa ótica, a literatura apresenta que os estudos sobre mudança organizacional podem ser organizados, em uma perspectiva evolutiva, em três correntes teóricas. A primeira contempla os trabalhos que utilizam como referência o modelo de Lewin e Gold (1999) de descongelamento, mudança e recongelamento. O primeiro estágio de descongelamento ocorre quando há o reconhecimento inicial do atual estado organizacional como sendo indesejável e inadequado, e por isso, ocorre o desejo de mudança. O estágio seguinte é o da mudança propriamente dita, nele algumas tentativas de transformação são introduzidas com vistas a tornar a nova situação mais adequada para o trabalho e para as pessoas. O terceiro estágio é aquele onde acontece o recongelamento, nessa situação quando as mudanças propostas são implantadas elas passam a ser incorporadas na rotina organizacional e no pensamento dos indivíduos que a ela pertencem. Assim, as novas atitudes, rotinas e práticas passam a incorporar o novo sistema operacional da organização (LEWIN; GOLD, 1999; MARQUES, 2012).

A segunda corrente teórica é aquela que apresenta as pesquisas sobre os aspectos ligados aos níveis organizacionais e sistêmicos, como missão e estratégia, políticas e normas, estrutura e outros fatores que influenciam a mudança organizacional (ROBERTSON, ROBERTS; PORRAS, 1993; KOTTER, 1995; KURTZ; DUNCAN, 1998; WOOD Jr., 2009). A última perspectiva abarca os estudos que buscam compreender o comportamento, as necessidades, os valores e as motivações individuais e suas influências para um bom desempenho dos esforços de mudança (COGHLAN, 1993; OREG, 2006; ERWIN; GARMAN, 2010; OREG; BERSON, 2011; MARQUES; MORAIS; ALBERGARIA, 2011; MARQUES, 2012). Todas essas linhas de pensamento, de acordo com Armenakis e Bedain (1999), Judson (1980) e Kotter (1995), procuraram compreender melhor a mudança em relação ao seu conteúdo, contexto e processo.

Na perspectiva estratégica, Greenwoods e Hinings (1996) apresentam uma tipologia para mudança organizacional. A estrutura é concebida em termos de prescrições ou moldes arquetípicos, originados por esquemas interpretativos e compartilhados socialmente, dentro de conceitos de mudança radical e convergente. Segundo os autores, mudança radical é uma ruptura na orientação da organização, isto é, um completo abandono da orientação existente 
desencadeando um processo de transformação da organização. Em oposição, mudança convergente seria um simples ajustamento na orientação existente, consistindo em uma leve adequação dentro dos parâmetros do mesmo molde arquetípico vigente.

Por sua vez Wood Jr., Curado e Campos (1994) acrescentam que a mudança organizacional pode ser conceituada como qualquer transformação que seja capaz de produzir impacto na organização parcial ou integralmente. Para esses autores a mudança pode ser classificada de três formas: a) quanto à sua natureza, nesse caso a mudança é relacionada com alguma característica da organização tal como estrutura, valores, cultura, gestão, entre outros; b) quanto à relação da organização com o ambiente, ou seja, a capacidade da organização em reagir proativa ou reativamente em resposta ao ambiente e, c) quanto à forma de implementação, podendo ser reeducativa, coercitiva ou racional.

O conceito de mudança organizacional mais apropriado para a análise das reações individuais à mudança organizacional é aquele em que a mudança organizacional é considerada como qualquer transformação formalmente planejada, nos componentes organizacionais, estrutura, processos, sistemas, cultura, política e pessoas (LINES, 2005; WOOD Jr.; CURADO; CAMPOS; 1994) que gera impacto na organização e nos resultados organizacionais (LIMA; BRESSAN, 2003). Nesse contexto, a mudança pode ser interpretada e respondida pelos membros da organização com diferentes comportamentos, conforme chamam a atenção Armenakis e Bedain (1999).

\subsection{Reações Individuais à Mudança}

A literatura que abarca as discussões sobre a temática mostra que as reações individuais à mudança apresentam-se de diversas formas. Giangreco e Peccei (2005) em um estudo sobre a privatização de uma empresa de energia elétrica na Itália, com 359 gerentes intermediários, identificaram que o comportamento do indivíduo pode ser ativo ou passivo, sendo o comportamento dominante o passivo, uma vez que a resistência assumia a forma de dissidência. Também Lines (2004; 2005) e semelhantemente Bovey e Hede (2001) constataram que o comportamento de resistência pode adotar diversas facetas indo desde uma categorização positiva até negativa com intensidade forte ou fraca em ambas as direções.

Estudos que consideraram que a resistência pode envolver as dimensões cognitiva, afetiva, e comportamental, revelaram grande variedade de reações individuais diante da mudança. Nessa abordagem, a resistência pode admitir a forma de uma atitude tripartite e 
assumir as três dimensões simultaneamente (PIDERIT, 2000; OREG, 2006; OREG; BERSON, 2011). A dimensão cognitiva envolve o modo como o indivíduo compreende a mudança, ou seja, suas crenças em relação ao fenômeno. O comportamento resistente seria decorrente da avaliação negativa da mudança, resultando em falta de comprometimento. Já na dimensão afetiva, o indivíduo experimenta emoções como ansiedade, raiva, medo, entusiasmo e apreensão. Esta dimensão está atrelada aos sentimentos que a mudança provoca. Finalmente, a dimensão comportamental é o modo como o indivíduo reage e comporta diante da mudança, podendo assumir desde um apoio entusiástico até a sabotagem deliberada (MARQUES, 2012). De acordo com Piderit (2000) o tipo de reação positiva ou negativa é resultante da soma das experiências anteriores com a intenção de agir futura.

Thomas e Hardy (2011) acrescentam ainda que a reação individual à mudança sofre influência direta dos significados construídos e compartilhados entre os indivíduos envolvidos no processo de mudança. Essas crenças, valores, emoções e visões individuais quando compartilhadas e combinadas podem formar comportamentos diante da mudança que nem sempre resultam em atitudes positivas e benéficas. Muitas vezes estes comportamentos podem também ser resultantes do mau gerenciamento da mudança por meio de formas impositivas e coercitivas. Assim, reconhecer a importância das emoções positivas e negativas que o funcionário vivencia no processo de mudança organizacional pode prover os líderes de informações relevantes para a condução e efetividade do processo, bem como identificar o potencial para comportamentos favoráveis ou desfavoráveis à mudança (NEVES, 2014; SANCHEZ-BURKS; HUY, 2009; KIEFER, 2005).

Outro fator que pode influenciar a percepção e a reação do indivíduo em relação ao processo de mudança diz respeito ao tempo de trabalho na organização. Quanto maior o tempo do empregado na organização mais negativo ele se torna em relação à mudança (CHUN; DAVIES, 2010). Corroborando, a pesquisa de Sinkovics, Zagelmeyer e Kusstatscher (2011) mostrou que mesmo após dez anos do acontecimento do processo de fusão da organização estudada, os indivíduos participantes do processo que permaneceram na organização não se integraram à nova realidade, e ainda apresentavam dificuldades de aceitar a mudança já ocorrida.

Assim, as pessoas podem apresentar diversas reações quando confrontadas com a mudança e isto dependerá: da personalidade do indivíduo, da natureza da mudança das atitudes destes em relação ao fenômeno, das forças que podem derivar de atitudes grupais, do contexto ambiental da organização (JUDSON, 1980), do contrato psicológico de trabalho 
(YAN; ZHU, 2013; ROUSSEAU, 1995), do tempo de duração do processo, das expectativas criadas em relação ao mesmo, do envolvimento formal do funcionário, da qualidade das relações interpessoais e da qualidade da relação com a organização (KIM; HORNUNG; ROUSSEAU, 2011; MARQUES; BORGES; NEVES, 2016) dos agentes da mudança, ou seja, dos líderes responsáveis pela condução do processo e também da intervenção dos superiores, se esta é incremental ou colaborativa (THOMAS; HARDY, 2011). O Quadro 1, adaptado de Judson (1980), Giancreco e Peccei (2005), sintetiza as diversas manifestações comportamentais que estão relacionadas à mudança organizacional.

\section{QUADRO 1 - Possíveis manifestações comportamentais em relação à mudança} organizacional

\begin{tabular}{|c|c|}
\hline $\begin{array}{l}\text { Reações à } \\
\text { mudança }\end{array}$ & Comportamento Observado \\
\hline Aceitação & $\begin{array}{l}\text { - aceitação e apoio entusiástico } \\
\text { - cooperação moderada } \\
\text { - cooperação sob orientação da gerência } \\
\text { - resignação passiva }\end{array}$ \\
\hline Indiferença & $\begin{array}{l}\text { - indiferença } \\
\text { - apatia } \\
\text { - perda de interesse pelo trabalho } \\
\text { - espera } \\
\text { - fazer somente o que for necessário }\end{array}$ \\
\hline $\begin{array}{l}\text { Resistência } \\
\text { Passiva }\end{array}$ & $\begin{array}{l}\text { - fazer somente aquilo que for ordenado - comportamento regressivo } \\
\text { - não aprender } \\
\text { - protestos } \\
\text { - trabalhar somente obedecendo as regras } \\
\text { - racionalizar recusas } \\
\text { - aceitação aparente (em seguida, retorno à formas antigas) } \\
\text { - ironia e prazer em falhar } \\
\text { - retirada pessoal (aumento do tempo fora do trabalho) } \\
\text { - desacelerar } \\
\text { - reter informações } \\
\text { - concordância verbal, porém sem execução concreta }\end{array}$ \\
\hline $\begin{array}{l}\text { Resistência } \\
\text { Ativa }\end{array}$ & $\begin{array}{l}\text { - fazer o menos possível } \\
\text { - reduzir o ritmo de trabalho } \\
\text { - retraimento pessoal } \\
\text { - cometer "erros" } \\
\text { - causar danos } \\
\text { - sabotagem deliberada } \\
\text { - crítica à gerência superior } \\
\text { - motivos para queixas } \\
\text { - recusa de carga de trabalho adicional } \\
\text { - apelação para o medo } \\
\text { - manipulação } \\
\text { - propagação de boatos e discussão } \\
\text { - obstrução e intimidação } \\
\text { - ridicularização }\end{array}$ \\
\hline
\end{tabular}

Fonte: Elaborado pelas autoras e adaptado de Judson (1980); Giancreco e Peccei (2005) 
Conforme mostra o Quadro 1, o comportamento apresentado pelos indivíduos em um contexto de mudança contempla possibilidades de respostas positivas e negativas, ou seja, entre as possíveis reações diante da mudança organizacional estão a cooperação de um lado e a resistência de outro. No entendimento de Kim, Hornung e Rousseau (2011) a aceitação é o engajamento sistemático e participativo do empregado que contribui e facilita a mudança organizacional planejada. Seria uma resposta positiva para que a mudança se efetive. Ao passo que a resposta negativa, a resistência, se caracteriza por um comportamento defensivo, cujo objetivo é a proteção do indivíduo dos efeitos da mudança, sejam eles reais ou imaginários, funcionando como um mecanismo de defesa consciente ou não (BOVEY; HEDE, 2001).

Em uma pesquisa sobre resistência à mudança no serviço público, Marques (2012) apresenta uma síntese das variáveis preditoras da resistência à mudança considerando aspectos individuais e organizacionais. As barreiras individuais seriam:

a) A insegurança econômica, principalmente pelo medo de perder o emprego ou as gratificações associadas aos cargos assumidos;

b) Medo do desconhecido, porque os indivíduos saem de uma situação conhecida para uma desconhecida e também pela falta de esclarecimento sobre o que vai mudar em sua vida no trabalho;

c) Ameaça ao convívio social, uma vez que podem alterar a estrutura e integridade dos grupos de trabalho;

d) Desestruturação de hábitos, por força da reformulação do trabalho e, dificuldade em reconhecer a necessidade de mudança, pois a tendência é ver apenas aquilo que se espera ver e uma informação incompleta e inacabada pode potencializar essa percepção e constituir-se como barreira à mudança.

Por variáveis organizacionais o autor apresenta a seguinte classificação:

a) A inércia estrutural, tendo em vista que as organizações se estruturam para obter estabilidade;

b) A inércia do grupo, mesmo quando os indivíduos aceitam ou queiram mudar o seu comportamento, o grupo pode agir como limitador e às vezes com represálias aos dissidentes;

c) A ameaça ao poder existente, já que as unidades que controlam o poder serão ameaçadas, além dos empregados temerem a alteração de recompensas, a perda de status, prestígio e poder e; 
d) A experiência anterior de mudança malsucedida ocorre quando grupos ou o sistema organizacional completo se tornam relutantes em aceitar a promoção de uma mudança nova em virtude de insucesso em processos no passado. A descrença ou recusa em acreditar que a mudança será implementada pode ser um forte fator de resistência (ARMENAKIS; BEDAIN, 1999).

Em síntese, é possível argumentar que compreender as reações dos indivíduos face aos processos de mudança pode ajudar a entender melhor as causas e consequências da sua ocorrência no ambiente organizacional. Além disso, os estilos de liderança podem influenciar as reações individuais à mudança proposta pela organização inibindo ou encorajando comportamentos cooperativos ou resistentes, como discutido na seção seguinte.

\section{ESTILOS DE LIDERANÇA}

A liderança é um aspecto do conhecimento humano que incita inquietações e debates, sendo um fenômeno que sempre chamou a atenção de pesquisadores. Estudiosos da psicologia social e do comportamento humano tentam há décadas descobrir quais os fatores que conduzem algumas pessoas à boa liderança e quais fatores que determinam sua aceitação. Nessa perspectiva, define-se liderança como um processo de influência sobre as pessoas e as tarefas executadas para a implementação das estratégias e alcance dos objetivos organizacionais (ROBBINS, JUDGE; SOBRAL, 2010). Em uma concepção mais abrangente que envolve a liderança eficaz, Fiedler (1967:11) define liderança como um relacionamento interpessoal, no qual as variáveis poder e influência são desigualmente distribuídas para que um indivíduo possa controlar e dirigir as ações e comportamentos dos outros na mesma proporção em que possa dirigir e controlar os seus.

Do ponto de vista de Fiedler (1967), a diferença entre as diversas interpretações sobre a liderança representam pontos de vista que não são necessariamente antagônicos e excludentes, mas que, de certa maneira, propõem complementaridades uns aos outros. É exatamente o conjunto de todos eles que oferece uma visão mais completa acerca da temática. Um exemplo disso, como explicam Yukl e Fleet (1994) e Bowditch e Buono (2003), é que a liderança tem sido definida em diversas abordagens que tratam sobre os traços e características individuais, passando pela perspectiva que esboça o comportamento dos 
líderes, a interação com os parceiros, o papel do relacionamento, a percepção dos seguidores e a influência sobre este, sobre a tarefa e sobre a cultura organizacional.

Por sua vez, Bass (1990) apresenta a liderança sob a ótica da gestão de mudança. Para ele a liderança é um processo centrado no grupo, com exercício de influência, persuasão e esforço de interação entre dois ou mais membros de um grupo. Este processo resulta em comportamentos específicos que conduzam ao alcance de metas e que frequentemente envolvem a estruturação ou reestruturação de uma dada situação relacionada à tarefa ou às relações humanas. Assim, os líderes são vistos como agentes de mudanças cujos atos afetam a vida das pessoas mais do que as outras pessoas afetam os atos deles. De tal maneira considera-se que embora o líder seja quem realmente inicia as ações, os seus seguidores precisam ser sensíveis a ele, às suas ideias e aos seus projetos (BASS, 1990; DIAS; BORGES, 2015).

Dessa maneira, assume-se nesse trabalho a abordagem que define a liderança como um processo de influência multidirecional entre líderes e liderado com propósito de efetivar uma mudança real e que permite uma ampliação do entendimento das pessoas sobre o que fazem, possibilitando maior envolvimento e comprometimento (BASS, 1990; YUKL, 2006). Com vistas a melhor compreensão sobre a temática, a seguir são apresentadas algumas teorias contemporâneas sobre o tema e a influência nas reações individuais à mudança organizacional.

Muitos dos modelos tradicionais de liderança seguem as diretrizes típicas da orientação transacional em liderança. De maneira análoga, em todas essas concepções os líderes exibem certos tipos de comportamentos e esperam em contrapartida uma reação dos seguidores em relação aos objetivos e metas organizacionais. Assim, um líder transacional enxerga essa relação líder-liderado como um processo de troca, onde o subordinado estabelece um vínculo com o líder condicionado a receber uma recompensa que já conhece antecipadamente. É um tipo de comportamento com resposta reflexiva, onde há interesse consciente de ambas as partes (HOLLANDER, 1978, YUKL, 1989).

Assim, a liderança transacional refere-se ao processo de utilização de incentivos para influenciar os esforços dos seguidores, no qual o líder deve deixar claro aos seguidores o que deve ser realizado para obtenção da recompensa, que pode ser na forma de prestígio ou dinheiro para cada meta ou objetivo realizado. Complementando, Burns (1978) e seus seguidores (BASS, 1985; BASS; AVOLIO, 1990) colocam que os líderes transacionais enfatizam sua capacidade de influência na garantia de atendimento das necessidades que os 
seguidores apresentam, a partir de uma lógica utilitarista onde a barganha ocorre entre a recompensa e a punição.

O líder transacional baseia sua ação na legitimidade e autoridade que lhe é conferida em termos formais para o exercício do poder, representando práticas que ratificam as normas, regras e padrões estabelecidos hierarquicamente e exigindo o cumprimento das tarefas previamente definidas. Não obstante, o líder transacional valoriza o alcance de objetivos e metas estabelecidas e a manutenção de um clima de concordância e apoio a ideias propostas, podendo lançar mão de recompensas e punições como estratégia para conseguir o comprometimento dos seguidores e para o controle dos comportamentos indesejáveis (BASS, 1985; BASS; AVOLIO, 1990; GOMES; CRUZ, 2007).

Por sua vez, o modelo de liderança transformacional envolve muito mais que o intercâmbio de experiências e influências entre líderes e liderados. Em vez disso, a liderança transformacional ocorre quando esses agentes interagem entre si de tal forma que ambos são elevados a um nível maior de motivação e moral em decorrência dessa interação. Assim, o líder tenta aumentar a sensibilidade dos seguidores sobre o que é certo e importante para motivá-los a realizar além das expectativas (DIAS; BORGES, 2015) e para promover mudanças nas atitudes dos liderados e na capacidade de participar ativamente dos processos de mudanças pretendidos pela organização (YUKL, 1989). Na literatura, a liderança transformacional é descrita como um estilo no qual o líder articula e compartilha uma visão de futuro com seus seguidores, considerando as diferenças individuais dos membros da equipe. Nesse tipo de liderança, o líder prefere interagir, procurar novas maneiras de trabalhar e buscar oportunidades face ao risco (GALLON; ENSSLIN, 2008). Para Bass e Avolio (1990) os líderes transformacionais não apenas reagem às circunstâncias ambientais, mas tentam moldá-las.

Dessa forma, a concepção da liderança transformacional está baseada no carisma, incorporando fortemente o componente pessoal à medida que os líderes incentivam os liderados a introduzir mudanças em suas atitudes de maneira a inspirá-los e influenciá-los na realização de objetivos sustentados em valores e ideais. Em geral os líderes que assumem esse estilo são mais visionários, inspiradores e imbuídos de ideais e metas específicas capazes de provocar sentimentos intensos em seus seguidores, parecem ter habilidades de empatia altamente desenvolvidas, que os auxiliam em suas percepções sobre as demais pessoas e sobre as necessidades de seus subordinados (BASS, 1985; BASS; AVOLIO, 1990). Além disso, Carvalho Neto (2010) acrescenta que os líderes transformacionais buscam ir além do 
instrumentalismo transacional e por isso são considerados agentes de mudança. Em geral, são designados para conduzir programas de mudança organizacional por sua capacidade de lidar com a resistência, de tomar decisões, de assumir riscos e confrontar a realidade. Os líderes transformacionais também enxergam o erro como uma possibilidade de aprendizado para enfrentar a complexidade e a incerteza.

Apresentado esse aporte teórico sobre mudança organizacional e estilos de liderança, a próxima seção apresenta os comportamentos de liderança que possuem relação com as reações individuais à mudança.

\section{ESTILO DE LIDERANÇA E REAÇÕES INDIVIDUAIS À MUDANÇA}

O comportamento do líder na condução do processo de mudança organizacional é um dos fatores que influenciam as reações individuais à mudança, influenciando sentimentos de ansiedade, mecanismos de defesa e até mesmo obstruindo a capacidade de adaptação do indivíduo à mudança (OREG, BERSON, 2011; CHOI, 2011). Nesse sentido, o surgimento da resistência depende principalmente, da maneira com que as mudanças são gerenciadas, das lideranças envolvidas na condução do processo, do quanto os indivíduos percebem a mudança como positiva ou negativa e do quanto eles estão comprometidos com os propósitos da organização (OREG; VAKOLA, ARMENAKIS, 2011; AVEY; WERNSING; LUTHANS, 2008; KRUGLANSKI et al., 2007).

Em uma situação de mudança, de acordo com Neves (2014) existem possibilidades do surgimento da resistência ativa, manifestada por meio de comportamentos do tipo: redução do ritmo de trabalho, diminuição da qualidade do trabalho propositalmente e até mesmo a sabotagem deliberada. Por outro lado, alguns indivíduos podem cooperar se perceberem que a mudança pode ser benéfica para eles (OREG et al. 2011). Assim, a resistência pode assumir desde a aceitação entusiástica e incondicional até a resistência passiva. Se o funcionário percebe boas oportunidades de carreira ou acha que os processos organizacionais mudarão para melhor, ele tende a cooperar com a mudança proposta pela organização. Por outro lado, se teme não atender às expectativas inerentes aos novos padrões definidos pelas mudanças ou acha que as mudanças são ruins para ele e para a organização, o indivíduo tende a resistir. O indivíduo pode ainda se manter neutro por não possuir uma opinião formada ou por vontade própria decidir não reagir ao processo de mudança iniciado ou implementado pela 
organização (MARQUES; MORAIS; ALBERGARIA, 2011; MARQUES, 2012). Este comportamento não é estático, pode alterar no decorrer de sua implementação tramitando de resistente para colaborativo, por exemplo. Além disso, para se defender e proteger o indivíduo pode concordar abertamente com a mudança, mas no dia a dia optar por não fazer nada para sua implementação, resistindo ativamente.

Muitas organizações, de acordo com Van Dick, Ulrich e Tissington (2006) fracassam na condução de seus processos de mudanças porque o estilo de gestão escolhido por seus dirigentes está pautado em pressupostos tecnicistas, desconsiderando a influência do fator humano. Ao contrário das expectativas dos empregados, muitos líderes tendem a usar a coerção, a burocracia, o controle exacerbado para obter a adesão pretendida ao programa de mudança. Esse comportamento é típico do líder transacional, conforme anteriormente mencionado, em que enfatiza padrões de trabalho, atribuições e tarefas orientadas para objetivos, concentra-se no resultado da tarefa, na disciplina do funcionário e confia exacerbadamente em recompensas e punições para influenciar o desempenho (DIAS; BORGES, 2015), podendo assim produzir uma reação individual onde existe descrédito e rejeição parcial ou integral à mudança pretendida e uma falta de confiança e ressentimento com o gestor (CHOI, 2011).

Lambert e Hogan (2010) acrescentam que gestores do tipo transacionais que utilizam a coerção para obter a adesão à mudança diminuem consideravelmente o grau de satisfação no ambiente de trabalho. Nessa perspectiva os membros da organização enxergam a mudança como uma ameaça para sua vida pessoal e profissional criando sentimentos de incerteza e ambiguidade (SEITJS; ROBERTS, 2011) que os fazem perceber e reagir de forma desfavorável a implementação da mudança. Além disso, fatores como a falta de investimento em comunicação, treinamento e acompanhamento da mudança propriamente dita faz com que os funcionários sintam que suas questões são ignoradas pela gerência e provocam um sentimento de desilusão com as mudanças pretendidas (LINES, 2005).

No estilo de liderança transacional, o comportamento do líder é direcionado para a orientação e acompanhamento do subordinado, para distribuição de recompensas com foco motivador, no sentido de se atingir metas e objetivos organizacionais (DIAS; BORGES, 2015). Assim, no contexto de uma mudança, os comportamentos típicos são: a) a recompensa contingente, que se refere à troca entre líderes e liderados, onde são oferecidas recompensas para o bom desempenho e ameaças para desempenhos ruins, onde o indivíduo pode optar em cooperar com a mudança e ser premiado com uma recompensa ou resistir (passiva ou 
ativamente) e ser ameaçado com um processo disciplinar, por exemplo; b) a administração por exceção ativa, onde os líderes monitoram os erros e os possíveis boicotes e agem corrigindo esses casos para não se transformarem em resistências ativas ou passivas; e c), a administração por exceção passiva, na qual os líderes intervêm somente quando os procedimentos e normas não estão sendo cumpridos, ou seja, quando ocorre indiferença, apatia ou resistência passiva em relação ao processo de mudança.

Assim, espera-se que em decorrência da orientação para a tarefa, o líder transacional utilize todas as ferramentas necessárias para implementar a mudança proposta pela organização. Com isso, o estilo de liderança transacional estaria mais associado ao comportamento resistente do funcionário quando comparado com o estilo de liderança transformacional. Nesse contexto, a seguinte hipótese é colocada como proposição para pesquisas futuras:

Hipótese 1: $O$ estilo de liderança transacional influenciará negativamente a aceitação individual à mudança organizacional.

Por outro lado, o estilo de liderança transformacional, de acordo com Bass (1985) é caracterizado por um processo onde o líder busca aumentar a sensibilidade dos seus seguidores do que é certo e importante, para motivá-los além das expectativas. Em situações de mudança, de muita incerteza e volatilidade é possível perceber a necessidade de se aproximar desses comportamentos de liderança transformacional. Como assumem um estilo mais proativo e não reativo esses líderes buscam romper com tradições oferecendo caminhos alternativos e soluções inovadoras (OREG; BERSON, 2011). Além disso, procuram descongelar padrões enrijecidos e institucionalizar novas condutas.

Robbins, Judge e Sobral (2010) afirmam que no atual cenário dinâmico, complexo e ambíguo, são necessários líderes que desafiem o status quo, criem visões de futuro e sejam capazes de inspirar os membros da organização a querer realizar essas visões. Parece então, que podem se tornar os tipos ideais em situações onde é necessário o restabelecimento do equilíbrio, mesmo que implique em uma passagem por períodos de transformação organizacional. Para Avolio e Bass (1991) e Bass (1990) esse tipo de papel desempenhado pelo líder faz com que as pessoas percam o medo do desconhecido e deixem de se sentir ameaçadas por uma possível perda de identidade.

Segundo Carvalho Neto (2010), os líderes transformacionais também são agentes de mudança, pois são designados para conduzir a organização em processos de transformações. Isso porque eles têm condições de lidar com a resistência, tomar uma posição, assumir riscos 
e confrontar a realidade vigente. Espera-se que o líder transformacional tenha a habilidade de estimular e implementar mudanças a partir do carisma e de sua visão de futuro, bem como de sua capacidade de comunicar e de estimular as pessoas a adotarem uma nova forma de ver as coisas. Bass e Avolio (1999) indicaram que os líderes transformacionais normalmente apresentam comportamentos associados a quatro características: a) influência idealizada, b) motivação inspiradora, c) estímulo intelectual e, d) consideração individualizada. Num processo de mudança a influência idealizada pode contribuir para uma reação de cooperação e apoio entusiástico, uma vez que o líder é um modelo para os seus seguidores, pois os incentiva a compartilhar visões e objetivos comuns, fornecendo uma visão clara do processo. Já a motivação inspiradora, onde o líder busca expressar claramente a importância dos objetivos desejados comunicando o nível de expectativas em torno dos mesmos, pode levar os indivíduos a reagir desde a cooperação e apoio entusiástico, passando pela cooperação moderada até a cooperação sob a orientação da gerência. Tais reações também podem ocorrer com os comportamentos de estimulação intelectual, onde o líder desafia seus seguidores na busca de solução de problemas, bem como no comportamento de consideração individualizada, onde os líderes direcionam grande parte do tempo ensinando e treinando seus seguidores de maneira individualizada. Portanto, a segunda hipótese é colocada para uma investigação futura:

Hipótese 2: O estilo de liderança transformacional influenciará positivamente a aceitação individual à mudança organizacional.

Em síntese, para Bass e Avolio (1999) os fatores que distinguem os líderes transformacionais estão relacionados à capacidade para demonstrar comportamentos que conduzem a mudanças positivas ao: a) estimular as pessoas a adotarem novas perspectivas sobre o trabalho, valorizando ideais e valores comuns a todos; b) envolver todos na concretização da missão e da visão organizacional que se pretende consolidar; c) promover comportamentos de comprometimento e eficácia no trabalho; e d) elevar a disponibilidade dos indivíduos em abdicarem de interesses meramente pessoais e fazerem sacrifícios quando se fizer necessário para o bem da coletividade. Em síntese, os líderes transformacionais buscam criar um ambiente organizacional que possibilita que a mudança dos valores dos liderados possa ocorrer, tornando-os mais conscientes do resultado da tarefa, para auxiliar no comprometimento com a visão e os objetivos da organização (YUKL, 2006).

Cabe, portanto, ressaltar que, o estilo de liderança pode ser apenas uma das variáveis que irão determinar se o indivíduo reagirá positiva ou negativamente em relação à mudança. 
Existem outras variáveis que conduzem o indivíduo a uma resposta de aceitação e apoio ou de resistência à mudança, mas que não são focos desse estudo.

\section{CONSIDERAÇÕES FINAIS}

Conforme afirmam diversos autores (LAWRENCE, 1954; MAURER, 1996; WADELL; SOHAL, 1998; DEL VAL; FUENTES, 2003) muitas iniciativas de mudança fracassam devido ao comportamento de resistência dos funcionários. Em geral, isso ocorre porque, segundo Seijts e Robert (2011), os funcionários não estão propensos a mudar porque acreditam que a mudança será ruim para eles e para a organização e por isso tem chances de fracassar.

Assim, considerando que em um processo de mudança ocorre uma alteração de uma situação conhecida para uma desconhecida e que a efetividade de sua implementação está relacionada com o comportamento de aceitação dos funcionários, este trabalho objetivou compreender a influência do estilo de liderança na cooperação ou resistência a mudança dos funcionários. As motivações para esse estudo se basearam nas discussões de Oreg e Berson (2011) que afirmam que apesar de considerar importantes as ações que os líderes tomam quando conduzem suas organizações em situações de mudança, pouca atenção tem sido dada na literatura para entender o fenômeno na ótica do empregado, apesar do frequente consenso de que o bom desempenho de uma mudança está na aceitação e comprometimento dos funcionários (BARTUNEK et al., 2006).

Visando entender melhor a relação entre as reações individuais à mudança e o estilo de liderança este estudo revisou a literatura dominante sobre esses temas. Em razão da existência de uma grande diversidade de abordagens teóricas e modelos explicativos sobre liderança, as hipóteses para pesquisa foram baseadas principalmente nos modelos de liderança transacional e transformacional. Em geral, as hipóteses colocadas para pesquisa discutem como o estilo de liderança influencia a reação individual à mudança organizacional. A ideia central é que o estilo de liderança transformacional tende a encorajar comportamentos positivos em relação à mudança organizacional porque o líder transformacional estimula e envolve os funcionários a realizar um esforço extra em direção às visões do próprio líder. Por outro lado, o líder transacional tende a estimular comportamentos resistentes à mudança organizacional porque 
utiliza instrumentos de controle e até mesmo punição caso os objetivos e as metas organizacionais não sejam atingidas pelos funcionários.

Espera-se que este estudo possa trazer contribuições teóricas a partir da literatura aqui consultada, uma vez que poucos estudos abordam os construtos estilos de liderança e mudança organizacional de maneira conjunta. Em sua aplicação em campo, possa também trazer contribuições práticas, sobretudo, sobre a compreensão se o estilo de liderança realmente tem sua relação com a resistência ou a aceitação à mudança organizacional. Possa contribuir com as organizações e indivíduos, no sentido de que estes reflitam mais sobre o comportamento da liderança nos processos de mudança organizacionais e que o incluam em suas agendas.

As organizações também podem usar os achados deste trabalho em processos de seleção, treinamento e desenvolvimento de líderes. Em relação aos líderes, as conclusões de uma pesquisa empírica podem sugerir qual (is) estilo (s) de liderança que eles devem assumir em situações de mudança, assim como o fazem no dia a dia com elementos como negociação, construção de estratégias e tantas outras responsabilidades e ferramentas de gestão. Ademais espera-se também maior entendimento sobre quais estilos de liderança são mais eficazes para serem adotados nos processos de implantação de mudanças organizacionais. A partir dessas propostas acredita-se que as possíveis aplicabilidades sugeridas nesse estudo possam ser testadas empiricamente. 


\section{REFERÊNCIAS}

ARMENAKIS, A.A; BEDAIN, A.G. Organizational change: A review of theory and research in the 1990s. Journal of Management, v.25, p.293-315, 1999.

AVEY, J.B.; WERNSING, T.S.; LUTHANS, F. Can positive employees help positive organizational change? Impact of psychological capital and emotions on relevant attitudes and behaviors. The Journal Applied Behavioral Science, v.44, n.1, p.48-70, 2008.

AVOLIO, B. J.; BASS, B. M. The full range of leadership development: basic and advanced manuals. Binghamton: Bass, Avolio \& Associates, 1991.

BARNETT, W. P. CARROL, G. R. Modelling Internal Organizational Change. Annual Review of Sociology, v. 21, p.217-236, 1995.

BARTUNEK, J.M; ROUSSEAU, D.M; RUDOLPH, J.W; DE PALMA, J. On the receiving end: Sensemaking, emotion, and assessments of an organizational change initiated by others. Journal of Applied Behavioral Science, v.42, p.182-206, 2006.

BASS, B. M. Leadership and performance beyond expectations. New York: Free Press, 1985.

BASS, B. M. From transactional to transformational. Leading to share the vision. Organizational Dynamics, 1990.

BASS, B. M.; AVOLIO, B. J. Developing transformational leadership: 1992 and beyond. Journal of European Industrial Training, Bingley, v.14, n.5, p.21-27, 1990.

BASS, B. M.; AVOLIO, B. J. Full range leadership development: manual for the multifactor leadership questionare. Redwood City, C. A: Mind Garden, 1999.

BERSON, Y; OREG, S.; DVIR T. CEO values, organizational culture and firm outcomes. Journal of Organizational Behavior, v.29, p.615-633, 2008.

BLUMENTHAL, B.; HASPESLAGH, P. Toward a definition of corporate transformation, Sloan Management Review, v.35, n.3, p.101-6, 1994.

BORGES, R.S.G.; MARQUES, A.L. Gestão da mudança: uma alternative para a avaliação do impacto da mudança organizacional. Revista FACES Journal, v.10, n.1, p.95-113, 2011.

BOVEY, W.; HEDE, A. resistance to organizational change: the role of defence mechanisms. Journal of managerial Psychology, v.16, n.7, p.534-548, 2001.

BOWDITCH, J. L.; BUONO, A. F. Elementos de Comportamento Organizacional. São Paulo: Thomson-Pioneira, 2003.

BURNS, J. M. Leadership. New York: Harper \& Row, 1978.

BURNS, J. M. Transactional and transforming leadership. In: WREN, J. T. The leader's companion. Free Press: Division of Simon and Schuster, New York, USA, 1995. 
CARVALHO NETO, A. M. A liderança transformacional e o perfil brasileiro de liderança: entre o cru e o cozido. In: NELSON, R. E.; SANT ANNA (orgs). Liderança: entre a tradição, a modernidade e a pós-modernidade. Rio de Janeiro: Elsevier, 2010.

CHOI, M. Employees' attitudes toward organizational change: a literature review. Human Resource Management, v.50, n.4, p.479-500, 2011.

CHUN, R.; DAVIES, G. The effect of merger on employee views of corporate reputation: timeand space dependent theory. Industrial Marketing Management, v.39, p.721-727, 2010.

COGHLAN, D. A person-centred approach to dealing with resistance to change. Leadership and Organization Development Journal, v.14, n.4, p.10-4, 1993.

DEL VAL, M. P.; FUENTES, C. M. Resistance to Change: a literature review and empirical study. Management Decision, v.41, n.2, p.148-155, 2003.

DIAS, M.A.M.J.; BORGES, R.S.G. Estilos de liderança e desempenho das equipes no setor público. Revista Eletrônica de Administração - REAd, v.80, n.1, p.200-221, 2015.

ERWIN, D. G.; GARMAN, A. N. Resistance to organizational change: linking research and practice. Leadership \& Organizational Development Journal, v.31, n.1, 2010.

FIEDLER, F. E. A theory of leadership effectiveness. New York: McGraw-Hill, 1967.

FUGATE, M; KINICKI, A.J; PRUSSIA, G.E. Employee coping with organizational change: An examination of alternative theoretical perspectives and models. Personnel Psychology, v.61, n.1, 2008.

GALLON, A. V.; ENSSLIN, S. R. Potencial de liderança criativa em equipes de trabalho de empresas de base tecnológica incubadas. RAI- Revista de Administração de Inovação. São Paulo, v.5, n.1, p.20-35, 2008.

GIANGRECO, A.; PECCEI, R. The nature and antecedents of middle manager resistance to change: evidence from the Italian context. International Journal of Human Resource Management, v.16, n.10, p.1812-29, 2005.

GOMES, A. R.; CRUZ, J. Abordagem carismática e transformacional: modelos conceptuais e contributos para o exercício da liderança. Revista de Psicologia da USP, São Paulo, v. 18, n.3, 2007.

GREENWOOD, R.; HININGS, C. R. Understanding Radical Organizational Change: bringing together the old and the new institutionalism. Academy of Management, v.21, n.4, p.1022-1054, 1996.

HOLLANDER, E. P. Leadership dynamics: a practical guide to effective relationships. New York: Free Press, 1978.

JUDSON, A. S. Relações Humanas e Mudanças Organizacionais. São Paulo: Atlas, 1980. 
KIM, T.; HORNUNG, S.; ROUSSEAU, D. M. Change-supportive employee behavior; antecedents and the moderating role of time. Journal of Management, v.37, n.6, p.1664-1693, 2011.

KRUGLANSKI, A.W. et al. "On the move" or "staying put": locomotion, need for clausure, and reactions to organizational change. Journal of Applied Social Psychology, v.37, n.6, p. 1305- 1340, 2007.

KOTTER, J. P. Leading Change: Why transformation Efforts Fail. Harvard Business Review v.73, n.2, p.59-67, 1995.

KOTTER, J.P.; SCHLENSINGER, L.A. Choosing strategies for change. Business Review. Paperback no. 90064, 1994.

KURTZ, P., DUNCAN, A. Shared service centres: overcoming resistance to implementation of a shared service centre. Management Accounting, v.76, n.7, p.47-48, 1998.

LAMBERT, E. G.; HOGAN, N. L. Wanting change: the relationship of perceptions of organizational innovation with correctional staff job stress, job satisfaction, and organizational commitment. Criminal Justice Police Review, v.21, n.2, p.160-184, 2010.

LAWRENCE, R. R. How to deal with resistance to change. Harvard Business Review, MayJune, p.49-57, 1954.

LEWIN, K. Field theory in social science. New York: Harper \& Row, 1951.

LEWIN, K.; GOLD, M. Group decision and social change. The Complet Social Scientist: A Kurt Lewin Reader. American Psychologial Association, Washington, DC, 265-84 (reprinted from Newcomb, T.M and Harthey, E. L (eds), 1948, Reading in Social Psychology, 330-41, Henry Holt, New York, NY. 1999.

LIMA, S. M. V.; BRESSAN, C. L. Mudança Organizacional: uma introdução. In: LIMA, S. M. V. (Ed.) Mudança Organizacional. Teoria e Gestão. Rio de Janeiro: Ed. FGV, 17-63, 2003.

LINES, R.The Influence of participation in strategic change: resistance, organizational commitment, and change goal achievement. Journal of Change Management, v. 4, n.3, p.193215, 2004.

LINES, R. The structure and function of attitudes toward organizational change. Human Resource Development Review, v.46, p.501-26, 2005.

MARQUES, A. L. Resistência à mudança e suas relações com o comprometimento, qualidade de vida e estresse no trabalho: Estudo da reforma gerencial do governo de MinasGerais. Tese de Professor Titular. UFMG, Belo Horizonte, 2012. 
MARQUES, A. L.; BORGES, R. S.; NEVES, L. A. Mudança organizacional e satisfação no trabalho: um estudo com servidores públicos do estado de Minas Gerais, Revista de Administração Pública, v.50, n.1, p.41-58, 2016.

MARQUES, A. L.; MORAIS, K.; ALBERGARIA, A. R. O gerenciamento de desempenho de servidores públicos: estudo sobre a cooperação e a resistência dos servidores à implantação da Avaliação de Desempenho individual pelo governo de Minas Gerais. XXXV EnANPAD, Rio de Janeiro/RJ, set, 2011.

MAS, A. Labour unret and the quality of production: evidence from the construction equipment resale market. Review of Economic Studies, v.75, n.1, 2008.

MAURER, R. Using resistance to built support to change. The Journal for Quality and Participation, v.19, n.3, p.56-66, 1996.

NADLER, D. A.; TUSHMAN, M. L. Beyond the charismatic leader: Leadership and organizational change. California Management Review, v.32, n.2, p.77-97, 1990.

NEIVA, E. R. Percepção de mudança individual e organizacional: o papel das attitudes e das características organizacional. 2004. 240 f. Tese (Doutorado em psicologia) - Instituto de Psicologia, Universidade de Brasília, Brasília, 2004.

NEVES, L. A. Reação individual à mudança de servidores do Instituto Federal de Minas Gerais em relação ao processo de fusão. Dissertação. UFMG, Belo Horizonte, 2014.

OREG, S. Personality, context, and resistance to organizational change. European Journal of Work and Organizational Psychology, v.15, p.73-101, 2006.

OREG, S; BERSON, Y. Leadership and employee`s reactions to change: the role of leader`s personal attributes and transformational leadership style. Personal Psychology, v.64, p.627$659,2011$.

OREG, S.; VAKOLA, M.; ARMENAKIS, A. Change recipient's reaction to organizational change: a 60- year review of quantitative studies. The Journal of Applied Behavioral Science, v.47, n.4, p.461-524, 2011.

PIDERIT, S. K. Rethinking resistance and recognizing ambivalence A multidimensional view of attitudes toward organizational change. Academy of Management Review, v.25, p.783-794, 2000 .

RAFFERTY, A.E; GRIFFIN, M.A. Perceptions of organizational change: A stress and coping perspective. Journal of Applied Psychology, v.91, p.1154-1162, 2006.

ROBERTSON, S. B.; ROBERTS, D. R.; PORRAS, J. I. Dynamics of planned organizational change: assessing empirical support for theoretical model. Academy of Management Journal, v.36, p.619-34, 1993.

ROBBINS, S. R.; JUDGE, T. A.; SOBRAL, F. Comportamento Organizacional: teoria e prática no contexto brasileiro. 14a . ed. São Paulo: Pearson, 2010. 
ROUSSEAU, D. M. Psychological contracts in organizations: Understanding written and unwritten agreements. Thousand Oaks, CA: Sage, 1995.

SANCHEZ-BURKS, J.; HUY, Q.N. Emotional aperture and strategic change: accurate recognition of collective emotions. Organization Science, v.20, n.1, p.22-34, JanuaryFebruary 2009.

SEIJTS, G. H.; ROBERTS, M. The impact of employee perceptions on change in a municipal government. Leadership \& Organization Development Journal, v.32, n.2, p. 190-213, 2011.

SINKOVICS, R.R.; ZAGELMEYER, S.; KUSSTATSCHER, V. Between merger and syndrome: the intermediary role of emotions in four cross-border M\&A. International Business Review, v.20, p.27-47, 2011.

SZABLA, D. B. A multidimensional view of resistance to organizational change: exploring cognitive, emotional and intentional responses to planned change across perceived change leadership strategies. Human Resource Development Quaterly, v.18, n.4, 2007.

THOMAS, R.; HARDY, L. D. S. Managing organizational change: negotiating meaning and power-resistance relations. Organization Science, v.22, n.1, p.22-41, 2011.

VAN DICK, R.; ULRICH, J.; TISSINGTON, P.A. working under a black cloud: how to sustain organizational identification after a merger. British Journal of Management, v.17, p.69-79, 2006.

WADELL, D.; SOHAL, A.S. Resistance a constructive tool for change management. Management Decision, v.36, n.8, p.543-548, 1998.

WOOD, T. JR.; CURADO, I. B.; CAMPOS, H. M. Vencendo a crise: mudança organizacional na Rhodia Farma. Revista de Administração de Empresas, v.34, n.5, p.67-79, 1994.

WOOD Jr., T. Mudança organizacional: uma introdução ao tema. WOOD Jr., T. (coord.). Mudança Organizacional. 5 ed. São Paulo: Atlas, 2009.

YAN, S.; ZHU, Y. Impact of psychological contract violation on interpersonal trust during mergers and acquisitions. Social Behavior and Personality, v.41, n.3, p.487-496, 2013.

YUKL, G. Leadership in organizations. Englewood Cliffs: Prentice Hall, 1989.

YUKL, G. Leadership in organizations. 6. Ed. New Jersey: Pearson Education, 2006

YUKL, G.; FLEET, D. D. Van. Theory and research on leadership in organizations. In: Dunnette, M. D. et al. Handbook of industrial and organizational Psychology. 2 ed. Palo Alto, California: Consulting Psychologists Press, 1994. 